\title{
Mechanics and Dynamics of Helical Milling Operations
}

\author{
Changyi Liu ${ }^{1, *}$ - Gui Wang2 - Matthew S. Dargusch ${ }^{2}$ \\ ${ }^{1}$ Nanjing University of Aeronautics \& Astronautics, College of Mechanical and Electrical Engineering, China \\ 2 The University of Queensland, School of Mechanical and Mining Engineering, Australia
}

\begin{abstract}
This paper presents analytical models dealing with time domain cutting forces and the time and frequency domain dynamics of helical milling operations. The cutting forces both on the side-cutting edges and on the end-cutting edges along the helical feed path are modelled by considering the tangential and the axial motions of the tool. The dual periodicity, which is caused by the spindle rotation, as well as the period of the helical feed of the cutting tool has been included. The models of the machining process dynamics and of the chatter stability problems are decomposed into two parts: the critical axial depth of cut, and the critical radial depth of cut, both of which are solved. The dynamics model allows the selection of processing parameters, including axial cutting depth, radial cutting depth, and spindle rotation velocity in the chatter-free zone and the prediction of chatter vibrations during helical milling. Experiments have also been performed for real machining observations in order to verify the chatter-free zone obtained from the analytical model.
\end{abstract}

Keywords: cutting, process modelling and planning, helical milling, cutting dynamics, chatter

\section{INTRODUCTION}

Helical milling has been applied to generate or enlarge boreholes by means of a milling tool being fed on a helical path into the work piece. It is an advanced hole-making technology, used mainly for typically difficult-to-cut materials. Helical milling is shown to be able to machine $\mathrm{H} 7$ quality holes with a surface finish of $0.3 \mu \mathrm{m} \mathrm{Ra}$ in hardened AISI D2 tool steel, and to be able to enhance the tool life [1]. Helical milling was utilized in the hole-making in carbon fibre-reinforced plastic, and the cutting force coefficients were identified and the mechanistic modelling technique was used to predict cutting forces [2]. The method was employed on CFRP-titanium layer compounds, to model the non-deformed chip geometries for the process, and to explain the effect of the helical feed on the cutting forces [3].

Accuracy and precision are important considerations for machining products along with efficiency and cost. The investigation of machining stability and chatter vibration is significant for process planning. Milling can be one of the most complicated cutting process. A cutting forces prediction model considering the tool's geometrical features and the tool-work piece interaction is the foundation for the chatter modelling. Most research analyses the cutting forces on discrete milling tools elements, and then integrates them to result in the cutting forces on cutting tools. The cutter is divided into a number of discrete disk elements along its axis, and each elements' surface is considered as the plane of cut [4] and [5]. The factors that influence milling forces during the multi-axis milling process, such as the varying lead and tilt angles, the cutting tool deflections and form errors, have been included [6] and [7].

During the helical milling processing, both side-cutting edges and end-cutting edges involved simultaneously is an important feature. The cutting forces of the end-milling process using a flat end milling tool considering both the side edge and the side edge cuttings simultaneously were modelled [8]. For helical milling operations, as well as plunge milling operations, axial feed is another feature that should not be neglected. By considering the rigid body motion of the cutter and three translational and torsional vibrations of the structure, models to predict cutting forces, vibrations, and the chatter stability in the frequency domain for plunge milling process have been presented [9] and [10].

The finite element method (FEM) and finite difference method have been applied as a novel approach to simulate the dynamics of the machining system. A coupled finite element (FE) model was created to simulate the dynamic properties at the tool end point of the whole mechanical system, including the tool, spindle, and machine tool frame [11]. FEM has also been used to model the dynamics and vibration. This approach simulates the process, simultaneously including both vibration and the chip formation [12]. With regard to machining dynamic effects, machining geometric defects have been modelled, and the dynamic displacements due to clamping and machining forces have been defined using FEM [13]. The resonance frequencies of the axial vibration mode of the milling tool were predicted using FEM model of the vibration milling tool and demonstrated that high-frequency vibrations superimposed onto the tool lead to stabilization of the 
milling process with superior surface finishes [14]. These FEM models reflected the physical processes in the machining system accurately and visually, but such approaches are time-consuming and require intensive computing resources.

Machining chatter was detected using on-process methods, such as acquiring and processing cutting forces, vibration signals and acoustics signals, or by using off-process methods [15]. A new method for the detection of chatter in the end-milling operation based on the wavelet transform has been suggested, which provides various ways to determine chatter characteristics real-time or post process [16]. Sound pressure, machining force and tool displacements are measured during the process to evaluate the stability of high-speed milling, and tool displacements are used as input data to simulate the chip thickness variation during the process [17].

Helical milling has been presented as an alternative enabling technology for drilling operations [1] to [3]. Recently, a few analyses of the cutting forces of the helical milling process have emerged [18] and [19]. Although the mechanisms and dynamics of special operations with axial feed characteristics, such as plunge milling and drilling, or with the tangential feed properties, such as multi-axis milling and circular milling, were investigated, the dynamics and the chatter stability model for helical milling or milling with axial feed have not been found.

The characteristics of the helical milling operation are discussed in this paper, including modelling the cutting force influenced by the axial feed; to build the dynamics model in the four degrees of freedom (DOF) cutting tool - machine tool vibration system, and to simulate the chatter limitation for both the axial cutting depth and the radial cutting depth. This research based on the analytical cutting forces model, combining the interactions both on the sidecutting edges and on the end-cutting edges of helical milling operations, focusing on the machining process dynamics model and chatter stability problems, which will dealt with into two parts: the critical axial depth of cut, and the critical radial depth of cut. Both the chatter stability limitations of the critical axial depth of cut and the critical radial depth of cut during helical milling process will be solved.

\section{CUTTING FORCE MODEL FOR HELICAL MILLING}

The motion curve of a certain point on the cutting edge of the milling tool performing helical milling is composed of the helical motion of the tool axis and the circular motion of the point relative to the axis. The diameter of the bore $\Phi_{B}$ and the endmill diameter $D_{m}$, the rotating angular velocity $\Omega_{h}$ of the helix feed, the axial feed speed $f_{v a}$ and the tangential feed speed $f_{v t}$, the tangential feed rate per tooth $f_{z t}$, the axial feed rate per tooth $f_{z a}$, the pitch of the helix curve of the reference frame $P$, and the spindle rotational velocity $\Omega$, are depicted in Fig. 1. To define the movement of the cutting tool, and the cutting force, an $X, Y, Z$ global coordinate system (GCS) is attached the work piece, and an $x, y, z$ local coordinate system (LCS) is attached to the cutter.

While modelling the cutting forces of the helical milling process, there have been two considerations that might also affect the dynamics of the helical milling process. One is the cutting force

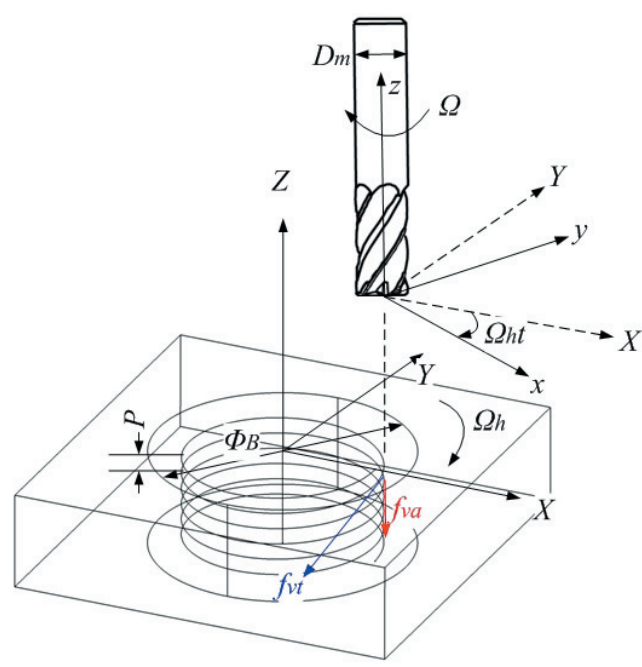

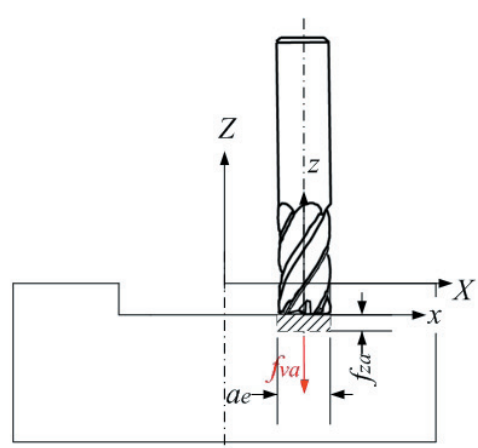

(Hole generating)

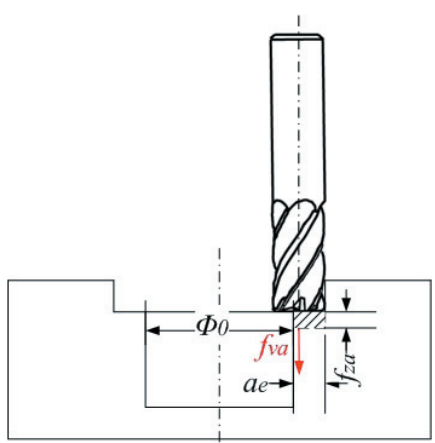

(Hole enlarging)

Fig. 1. Schematics of helical milling 
fluctuating periodically as a result of the cutting tool circumferential feed; the other is the cutting force component due to the cutting tool axial feed. The axial feed force mostly occurs at the end-cutting edge of the milling tools. The detailed interpretation and the development of the relative equations in this section refer to the authors' previously published literature [18]. The cutting forces loaded on the tool are a combination of side-edge cutting forces and end-edge cutting forces; these two parts are modelled and then summarized:

$$
\vec{F}=\vec{F}^{i}+\vec{F}^{*}
$$

where, $\vec{F}^{i}$ and $\vec{F}^{*}$ are cutting force components on the side-cutting edge and on the end-cutting edge, respectively.

The cutting force components on the $j^{\text {th }}$ endcutting edge to the LCS coordinate can be represented as:

$$
\left\{\begin{array}{c}
F_{x, j}{ }^{*} \\
F_{y, j}{ }^{*} \\
F_{z, j}{ }^{*} \\
T_{j}^{*}
\end{array}\right\}=\left[\begin{array}{cccc}
-\cos \varphi_{\mathrm{j}} & 0 & 0 & 0 \\
0 & \sin \varphi_{\mathrm{j}} & 0 & 0 \\
0 & 0 & 1 & 0 \\
0 & 0 & 0 & 1
\end{array}\right]\left([\Theta]\left[K^{*}\right]\left\{\begin{array}{c}
f_{z a} \\
1
\end{array}\right\}\right),(2
$$

where $K_{v c}^{*}, K_{v e}^{*}, K_{n c}^{*}, K_{n e}^{*}$ are the cutting force constants on the end-cutting edges along the circumferential and normal directions respectively,

$$
\begin{aligned}
& {\left[K^{*}\right]=\left[\begin{array}{ll}
K_{v c}^{*} & K_{v e}^{*} \\
K_{n c}^{*} & K_{n e}^{*} \\
K_{r c}^{*} & K_{r e}^{*}
\end{array}\right],} \\
& {[\Theta]=\int_{\frac{D_{m}}{2}-a_{e}^{*}}^{\frac{D_{m}}{2}} d r\left[\begin{array}{ccc}
\cos \theta & -\sin \theta & 0 \\
\sin \theta & \cos \theta & 0 \\
0 & 0 & 0 \\
r \cos \theta & -r \sin \theta & 0
\end{array}\right], A=\frac{N_{m} f_{z a}}{2 \pi},}
\end{aligned}
$$

$B=\frac{N_{m} f_{z t} \cos \varphi_{j}}{2 \pi}, \theta=\arg \tan \frac{A}{r+B}, \phi_{j}$ is the relative

rotational angle of the cutting tooth $j, r$ is the distance from centre point to a certain point on the end-cutting edge.

The side-cutting edge force components are added to the end-cutting force components on the $j^{\text {th }}$ tooth, then converted to GCS coordinates.

$$
\left\{\begin{array}{c}
F_{X, j} \\
F_{Y, j} \\
F_{Z, j} \\
T_{Z, j}
\end{array}\right\}=\left[\begin{array}{cccc}
\cos \Omega_{h} t & \sin \Omega_{h} t & 0 & 0 \\
-\sin \Omega_{h} t & \cos \Omega_{h} t & 0 & 0 \\
0 & 0 & 1 & 0 \\
0 & 0 & 0 & 1
\end{array}\right]\left\{\begin{array}{c}
F_{x, j}{ }^{i}+F_{x, j}{ }^{*} \\
F_{y, j}{ }^{i}+F_{y, j}{ }^{*} \\
F_{z, j}{ }^{i}+F_{z, j}{ }^{*} \\
T_{j}^{*}{ }^{*}
\end{array}\right\} \text { (3) }
$$

Finally, the superposition of all the cutting forces on the $N_{m}$ cutting teeth is the cutting forces on the cutting tool. The established time domain analytical cutting forces model for helical milling operations reflects both the cutting process on the side-cutting edge and on the end-cutting edge, incorporating the influence of the spindle motion and the tool helical feed.

\section{DYNAMICS OF HELICAL MILLING}

Helical milling is a typical interrupted cutting operation with a tangential feed and an axial feed. The machine tool-spindle-milling tool system was considered to be flexible in four degrees of measurement (DOM), i.e. in the global $X, Y, Z$ and $C$ directions, as shown in Fig. 2. This flexibility could lead to chatter instability if the axial depth of cut, the radial depth of cut and the spindle rotation speed were not selected properly.

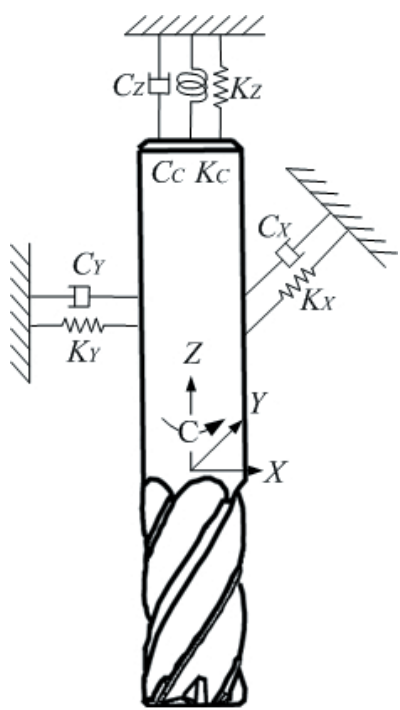

Fig. 2. Four DOM dynamics system of helical milling

The proposed cutting force model was used to build the dynamics model of the helical milling system and to predict the limitation of the chatter stability. Based on the regenerative chatter mechanism, the time domain dynamics relationship between the cutting force and dynamic displacement can be expressed as: 


$$
[M]\{\ddot{R}(t)\}+[C]\{\dot{R}(t)\}+[K]\{R(t)\}=\{F(t)\},
$$

where $R$ is the dynamic displacement or amplitude vector with four components $X, Y, Z$ and $C$. From the proposed cutting forces model, the cutting forces have a functional relationship with $a_{p}, a_{e}, f_{z t}, f_{a t}, \Omega$, $\Omega_{h}$ etc. The objective of chatter prediction during the helical milling operations should be to find the proper relationship between $a_{p}, a_{e}$, and $\Omega$ in order to avoid chatter vibration. To find the chatter lobe including the $a_{p}, a_{e}, \Omega$ directly is difficult. Therefore, a certain level of idealization and assumption has to be introduced. According to the cutting forces model that resulted from cutting forces on the side-cutting edges and cutting forces on the end-cutting edges, the dynamics model and chatter limitation problem was decomposed into two parts: the $X$ and $Y$ direction, and $Z$ and $C$ direction.

\subsection{The Chatter Limitation of Axial Depth of Cut}

The $X$ and $Y$ components of the cutting forces on the cutting tools mainly result from the interaction of the side-cutting edges, because the magnitude of the interaction on the end-cutting edges is smaller, and their sum is almost zero. Hence, the axial depth of cut is affected by the $X$ and $Y$ components of the cutting forces.

Regenerative chatter is the result of variation in the dynamic chip thickness as depicted in Fig. 3. The variation of dynamic chip thickness can be described as:

$$
\begin{aligned}
\Delta h\left(\varphi_{j}\right) & =h_{s t}-h\left(\varphi_{j}\right)= \\
& =f_{z t} \sin \varphi_{j}-\left(\Delta x \sin \varphi_{j}+\Delta y \cos \varphi_{j}\right) .
\end{aligned}
$$

If the edge effect is neglected, and the dynamic chip thickness into the side-cutting edge forces model is substituted, the sum of cutting forces on the $N_{m}$ flutes can be given as, (Eq. (6)):
For helical milling operations, transform to the $X-Y$ coordinates,

$$
\left\{\begin{array}{l}
\mathrm{F}_{X} \\
\mathrm{~F}_{Y}
\end{array}\right\}=\frac{1}{2} K_{t c}^{t} a_{p}\left[A_{X Y}\right]\left\{\begin{array}{l}
\Delta x \\
\Delta y
\end{array}\right\},
$$

where, $\left[A_{X Y}\right]=\left[\begin{array}{cc}\cos \left(\Omega_{h} t\right) & \sin \left(\Omega_{h} t\right) \\ -\sin \left(\Omega_{h} t\right) & \cos \left(\Omega_{h} t\right)\end{array}\right]\left[A_{x y}\right]$ are the time-varying directional dynamic helical milling force coefficients. If the influence of the $\Omega_{h}$ was neglected, the procedure to obtain the approximate solution could be identical with that in literature [5].

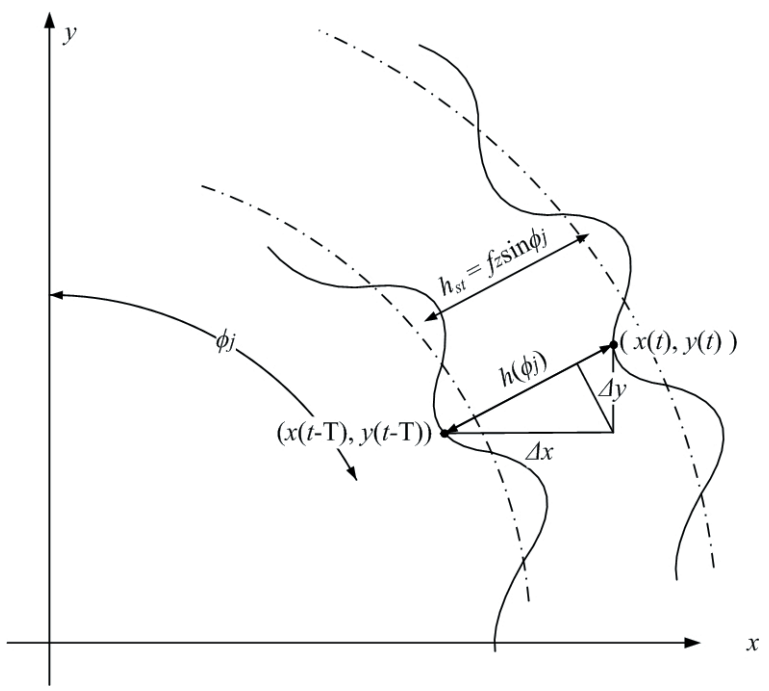

Fig. 3. Dynamic chip thickness variation in $x$ and $y$ direction

Considering the $X$ and $Y$ force components, and the Fourier transform, Eq. (4) becomes Eq. (8).

$$
\left\{[K]-\omega^{2}[M]+i \omega[C]\right\}\{R(\omega)\}=\{F(\omega)\} .
$$

The critical chatter frequency of the spindle is $\omega_{c}$,

$$
\left\{R\left(\omega_{c}\right)\right\}=\left[\mathrm{G}\left(\omega_{c}\right)\right]\left\{F\left(\omega_{c}\right)\right\},
$$

where $[G(\omega)]$ is the transfer function, or frequency response function. From Eq. (5), a frequency-

$$
\left\{\begin{array}{l}
F_{x}^{i} \\
F_{y}^{i}
\end{array}\right\}=\sum_{j=1}^{N_{\mathrm{m}}} \frac{1}{2} a_{p} g_{j}\left[\begin{array}{cc}
-K_{\mathrm{tc}}^{i} \sin 2 \varphi_{j}-K_{\mathrm{rc}}^{i}\left(1-\cos 2 \varphi_{j}\right) & -K_{\mathrm{tc}}^{i}\left(1+\cos 2 \varphi_{j}\right)-K_{\mathrm{rc}}^{i} \sin 2 \varphi_{j} \\
K_{\mathrm{tc}}^{i}\left(1-\cos 2 \varphi_{j}\right)-K_{\mathrm{rc}}^{i} \sin 2 \varphi_{j} & K_{\mathrm{tc}}^{i} \sin 2 \varphi_{j}-K_{\mathrm{rc}}^{i}\left(1+\cos 2 \varphi_{j}\right)
\end{array}\right]\left\{\begin{array}{c}
\Delta x \\
\Delta y
\end{array}\right\}=\frac{1}{2} K_{\mathrm{tc}}^{i} a_{p}\left[A_{x y}\right]\left\{\begin{array}{c}
\Delta x \\
\Delta y
\end{array}\right\},
$$

where $g_{j}=\left\{\begin{array}{ll}1, & \varphi_{j} \in\left[\Phi_{s t}, \Phi_{e x}\right] \\ 0, & \varphi_{j} \notin\left[\Phi_{s t}, \Phi_{e x}\right]\end{array}\right.$, and $K_{r c}^{i}=k_{r} K_{t c}^{i}$. 
dependent dynamic chip thickness vector as in Fig. 3 shown,

$$
\begin{aligned}
& \left\{\Delta R\left(\omega_{c}\right)\right\}=\left\{\begin{array}{l}
\Delta X\left(\omega_{c}\right) \\
\Delta Y\left(\omega_{c}\right)
\end{array}\right\}=\left\{R\left(\omega_{c}\right)\right\}-\left\{R_{0}\left(\omega_{c}\right)\right\}= \\
& =\left(1-\mathrm{e}^{-\mathrm{i} \omega_{c} T}\right)\left\{R\left(\omega_{c}\right)\right\}=\left(1-\mathrm{e}^{-\mathrm{i} \omega_{c} T}\right)\left[\mathrm{G}\left(\omega_{c}\right)\right]\left\{F\left(\omega_{c}\right)\right\} .
\end{aligned}
$$

Substitute Eq. (10) to Eq. (9), we obtain:

$$
\begin{aligned}
\left\{F\left(\omega_{c}\right)\right\}= & \frac{1}{2} K_{t c}^{i} a_{p}\left(1-\mathrm{e}^{-\mathrm{i}_{c} T}\right) . \\
& \cdot\left[A_{X Y}\left(\omega_{c}\right)\right]\left[\mathrm{G}\left(\omega_{c}\right)\right]\left\{F\left(\omega_{c}\right)\right\} .
\end{aligned}
$$

The characteristic function of Eq. (11) is:

$$
[I]-\frac{1}{2} K^{i}{ }_{t c} a_{p}\left(1-\mathrm{e}^{-\mathrm{i} \omega_{c} T}\right)\left[A_{X Y}\left(\omega_{c}\right)\right]\left[\mathrm{G}\left(\omega_{c}\right)\right]=0 .
$$

The response function has a nontrivial solution only if its determinant is zero, therefore, $\operatorname{det}\left|[\mathrm{I}]+\Lambda\left[A_{X Y}\left(\omega_{c}\right)\right]\left[\mathrm{G}\left(\omega_{c}\right)\right]\right|=0$, and the nontrivial solution of Eq. (11) exists. Where $\Lambda$ is the eigenvalue of Eq. (12), and the vibration system has the critical chatter frequency.

Experimental modal analysis was performed to extract the modal parameters of the helical milling tool-machine tool system. The frequency response function (FRF) $[\mathrm{G}(\omega)]$ of the milling tool attached to a Mikron 710 machining centre was identified through hammer impact modal tests, as described in the literature [20].

In order to describe the directional dynamic helical milling force coefficients $\left[A_{X Y}(\omega)\right]$, the zero order approximation of its Fourier series expansion was applied, and a single frequency solution derived. The predicted stability lobe identifying the critical axial depth of cut (aplim) and spindle speed to construct the lobes can be determined, as depicted in Fig. 4.

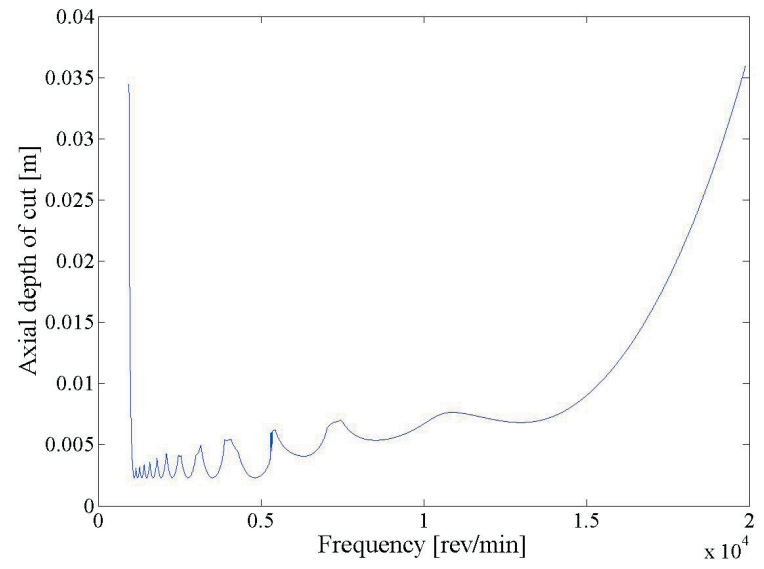

Fig. 4. The stability lobes prediction of axial depth of cut

\subsection{The Chatter Limitation of Radial Depth of Cut}

The $Z$ and $C$ components of cutting force $\left(F_{Z}, T\right)$ on the cutting tools mainly result from the interaction of the end-cutting edges, because the end-cutting edges engage predominantly in the axial feed direction and create continuous cutting. Hence, the radial depth of cut is affected by the $Z$ and $C$ components of cutting forces.

Considering the influence of the dynamic chip thickness on the axial vibration and torsional vibration, as presented in the literature, the regenerative chatter in the $Z$ and $C$ direction is the result of the variation in the dynamic chip thickness with period $\tau_{0}$ as depicted in Fig. 5. The variation of dynamic chip thickness can be described as:

$h\left(\varphi_{j}\right)=h_{Z}-\Delta h_{\varphi}=\left(\Delta Z\left(\varphi_{j}\right)-f_{z a} \Delta \varphi_{j} / \Phi_{p}\right) / \cos \theta$

a)

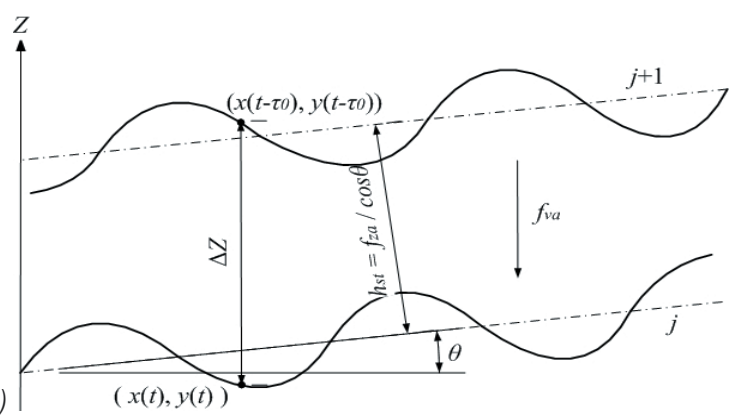

b)

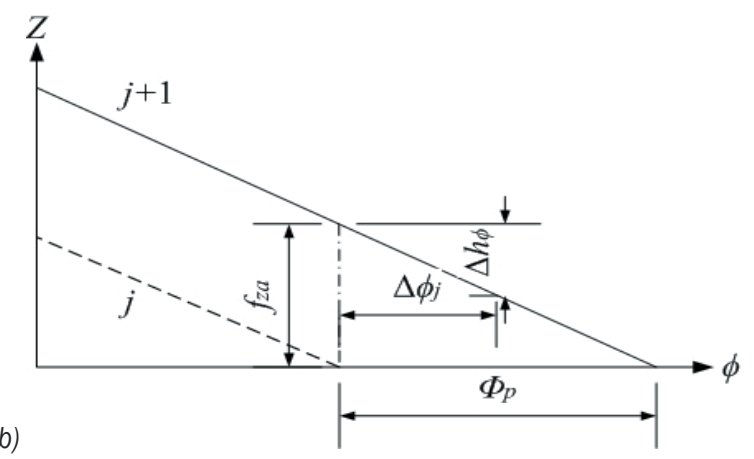

Fig. 5. Dynamic chip thickness variation in a) $Z$ and b) $C$ direction

Neglecting the edge effect on the end-cutting edges, and substituting dynamic chip thickness into the end-cutting edge force model results in the following relation:

$$
\begin{aligned}
\left\{\begin{array}{c}
\mathrm{d}_{a, j}^{*} \\
\mathrm{dT}_{\mathrm{j}}^{*}
\end{array}\right\}= & \left\{\begin{array}{c}
\Delta Z \\
\Delta \varphi_{j}
\end{array}\right\} K_{\mathrm{vc}}^{*} d r . \\
& \cdot\left[\begin{array}{cc}
\tan \theta+k_{n}^{*} & -\left(\tan \theta+k_{n}^{*}\right) f_{z a} / \Phi_{p} \\
r-k_{n}^{*} r \tan \theta & -\left(r-k_{n}^{*} r \tan \theta\right) f_{z a} / \Phi_{p}
\end{array}\right],
\end{aligned}
$$


where, $K_{n c}^{*}=k_{n}^{*} K_{v c}^{*}$. Integrating Eq. (15), the dynamic cutting forces on an end-cutting edge can be described as,

$$
\left\{\begin{array}{c}
F_{a, j}^{*} \\
T_{j}^{*}
\end{array}\right\}=\left.K_{v c}^{*}\left[\begin{array}{cc}
A \ln |r+B|+k_{n}^{*} r & -\left(A \ln |r+B|+k_{n}^{*} r\right) f_{z a} / \Phi_{p} \\
\frac{1}{2} r^{2}-k_{n}^{*} A(r-B \ln |r+B|) & -\left(\frac{1}{2} r^{2}-k_{n}^{*} A(r-B \ln |r+B|)\right) f_{z a} / \Phi_{p}
\end{array}\right]\left\{\begin{array}{c}
\Delta Z \\
\Delta \varphi_{j}
\end{array}\right\}\right|_{\frac{D_{m}}{2}-a_{e}} ^{\frac{D_{m}}{2}} .
$$

Sum up all the flutes and dynamic cutting force components on the cutting tool $\left(F_{Z}, T\right)$ as follows:

$$
\left\{\begin{array}{c}
F_{Z} \\
T
\end{array}\right\}=\sum_{j=1}^{N_{m}}\left\{\begin{array}{c}
F_{Z, j} \\
T_{j}
\end{array}\right\}=K_{v c}^{*}\left[A_{Z \Phi}(t)\right]\left\{\begin{array}{c}
\Delta Z \\
\Delta \varphi
\end{array}\right\}
$$

where the directional dynamic helical milling force coefficients are:

$$
\left.\left[A_{Z \Phi}(t)\right]=\sum_{j=1}^{N_{m}}\left(\begin{array}{c}
\left(1-f_{z a} / \Phi_{p}\right) \cdot \\
A \ln \left|\frac{\frac{D_{m}}{2}+B}{\frac{D_{m}}{2}+B-a_{e}}\right|+k_{n}^{*} a_{e} \\
\frac{D_{m}}{2} a_{e}-\frac{1}{2} a_{e}{ }^{2}-k_{n}^{*} A a_{e}+k_{n}^{*} A B \ln \left|\frac{\frac{D_{m}}{2}+B}{\frac{D_{m}}{2}+B-a_{e}}\right|
\end{array}\right\}\right) .
$$

The $Z$ and $C$ components of the displacement are:

$$
\begin{aligned}
& \{R(\mathrm{t})\}=\left\{\begin{array}{l}
Z(t) \\
\varphi(t)
\end{array}\right\}, \quad\left\{R_{0}(\mathrm{t})\right\}=\left\{\begin{array}{l}
Z(t-T) \\
\varphi(t-T)
\end{array}\right\}, \\
& \{R(\omega)\}=\left\{\begin{array}{l}
Z(\omega) \\
\varphi(\omega)
\end{array}\right\}, \quad\left\{R_{0}(\omega)\right\}=\mathrm{e}^{-\mathrm{i} \omega_{c} T}\{R(\omega)\}, \\
& \{\Delta(\omega)\}=\left\{\begin{array}{l}
\Delta Z(\omega) \\
\Delta \varphi(\omega)
\end{array}\right\}=\{R(\omega)\}-\left\{R_{0}(\omega)\right\}= \\
& =\left(1-\mathrm{e}^{-\mathrm{i} \omega T}\right)\{R(\omega)\}=\left(1-\mathrm{e}^{-\mathrm{i} \omega T}\right)[\mathrm{G}(\omega)]\{F(\omega)\} .
\end{aligned}
$$

Substitute Eq. (18) to Eq. (16), for the chatter frequency $\omega_{c}$, then:

$$
\begin{aligned}
\left\{F\left(\omega_{c}\right)\right\}= & K_{v c}^{*}\left(1-\mathrm{e}^{-\mathrm{i} \omega_{c} T}\right)\left[A_{Z \Phi}\left(\omega_{c}\right)\right] . \\
& {\left[\mathrm{G}\left(\omega_{c}\right)\right]\left\{F\left(\omega_{c}\right)\right\} . }
\end{aligned}
$$

The characteristic function of Eq. (19) is:

$$
[I]-K_{v c}^{*}\left(1-\mathrm{e}^{-\mathrm{i} \omega_{c} T}\right)\left[A_{Z \Phi}\left(\omega_{c}\right)\right]\left[\mathrm{G}\left(\omega_{c}\right)\right]=0 .
$$

Theoretically, similar to the aforementioned resolution approach to the chatter limitation of $a_{p}$, when $\operatorname{det}[\mathrm{I}]+\Lambda\left[A_{Z \Phi}\left(\omega_{c}\right)\right]\left[\mathrm{G}\left(\omega_{c}\right)\right] \mid=0$, the non- trivial solution of Eq. (19) exists, $\Lambda$ is the eigenvalue of Eq. (20). However, for the directional dynamic helical milling force coefficients $\left[A_{Z \Phi}(t)\right]$ the situation is more complicated, and the variable $a_{e}$ is not linear.

In the range from 0 to the end-edge length $\left(D_{m} / 2\right.$, half the tool diameter), $\left[A_{Z \Phi}(t)\right]$ can be simplified to:

$$
\left[A_{Z \Phi}(t)\right]=\sum_{j=1}^{N_{m}}\left\{\begin{array}{c}
k_{n}^{*} a_{e} \\
\frac{D_{m}}{2} a_{e}-\frac{1}{2} a_{e}^{2}
\end{array}\right\} \begin{cases}1 & \left.-f_{z a} / \Phi_{p}\right\} .\end{cases}
$$

If the influence of the $f_{z a}$ was neglected, the procedure to obtain the approximate solution would be identical with that in literature [9]. It is then necessary to solve the eigenvalue and obtain the predicted stability lobe that identifies the critical radial depth of cut $\left(a_{e}\right.$ lim) and the spindle speed, as shown in Fig. 6.

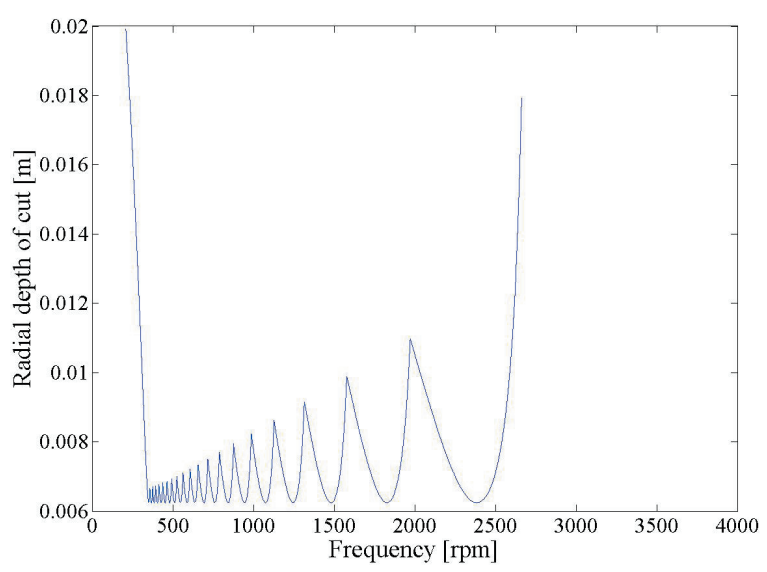

Fig. 6. The s tability lobes prediction of radial depth of cut

\section{EXPERIMENTAL METHODS}

The chatter-free machining experiments of helical milling process were performed under dry conditions. The radial cutting depth of $a_{e}$, cutting velocity of $v_{c}$, 
axial feed rate of $f_{z a}$, and tangential feed rate of $f_{z t}$ are independent processing parameters, on which spindle frequency $n$ and axial cutting depth $a_{p}$ depend. The experiments were designed to orthogonal trails with three variable factors $\left(a_{e}, v_{c}, f_{z a}\right)$ where each factor had three levels. The range of $n, a_{p}$ and $a_{e}$ based on the solved stability lobe diagrams shown in Figs. 4 and 6, along with the recommendations of the milling tool manual and the consideration that the processing parameters would be suitable for the finishing operation. All the processing parameters were depicted in Table 1.

The rough wrought Ti6A14V alloy blank has the geometry of a cuboid (160 mm width, $160 \mathrm{~mm}$ length, and $20 \mathrm{~mm}$ height) with a hole in a diameter of 60 $\mathrm{mm}$ in the centre as depicted in Fig. 1. M.A. Ford 20 mm 5-flute flat end cylindrical carbide milling tools (17878703A) were employed.

The occurrence of chatter could be detected by measuring the amplitude of the cutting forces, as well as the machining accuracy (surface roughness, roundness, and cylindricity). Once chatter occurs, the cutting force amplitude increases drastically, the surface roughness escalates, and the geometric accuracy of the hole is lost.

Experiments were performed on a five-axis Mikron UCP-710 machining centre. A Kistler 9265B piezo-electric dynamometer, a Mahr S3P 2D surface profile tester, and a Hexagon 3D coordinate measuring machine were setup to measure the cutting forces, machined surface roughness, roundness and cylindricity, respectively.

Table 1. Helical milling experiment parameters

\begin{tabular}{ccccccc}
\hline $\begin{array}{c}\text { Test } \\
\text { No. }\end{array}$ & $\begin{array}{c}v_{c} \\
{[\mathrm{~m} / \mathrm{min}]}\end{array}$ & $\begin{array}{c}n \\
{[\mathrm{rmm}]}\end{array}$ & $\begin{array}{c}a_{e} \\
{[\mathrm{~mm}]}\end{array}$ & $\begin{array}{c}a_{p} \\
{[\mathrm{~mm}]}\end{array}$ & $\begin{array}{c}f_{z a} \\
{[\mathrm{~mm} / \text { tooth }]}\end{array}$ & $\begin{array}{c}f_{z t} \\
{[\mathrm{~mm} / \mathrm{tooth}]}\end{array}$ \\
\hline 1 & 100 & 1591 & 0.25 & 1.5 & 0.48 & 0.060 \\
\hline 2 & 100 & 1591 & 0.5 & 1.5 & 0.60 & 0.075 \\
\hline 3 & 100 & 1591 & 0.75 & 1.5 & 0.72 & 0.090 \\
\hline 4 & 120 & 1910 & 0.25 & 1.5 & 0.72 & 0.090 \\
\hline 5 & 120 & 1910 & 0.5 & 1.5 & 0.48 & 0.060 \\
\hline 6 & 120 & 1910 & 0.75 & 1.5 & 0.60 & 0.075 \\
\hline 7 & 135 & 2149 & 0.25 & 1.5 & 0.60 & 0.075 \\
\hline 8 & 135 & 2149 & 0.5 & 1.5 & 0.72 & 0.090 \\
\hline 9 & 135 & 2149 & 0.75 & 1.5 & 0.48 & 0.060 \\
\hline
\end{tabular}

\section{EXPERIMENTAL RESULTS AND DISCUSSION}

The inspection of the operation accuracy, including the surface roughness of the inner surface of the hole, the roundness of the hole cross section, and the cylindricity of the hole were measured, and shown in Table 2.

Table 2. Helical milling experiment results

\begin{tabular}{cccc}
\hline $\begin{array}{c}\text { Test } \\
\text { No. }\end{array}$ & $\begin{array}{c}\text { Surface roughness } \\
{[\mu \mathrm{m}]}\end{array}$ & $\begin{array}{c}\text { Roundness } \\
{[\mu \mathrm{m}]}\end{array}$ & $\begin{array}{c}\text { Cylindricity } \\
{[\mu \mathrm{m}]}\end{array}$ \\
\hline 1 & $<1.6$ & $3.6,4.7,5.4$ & 7.01 \\
\hline 2 & $<1.6$ & $4.8,5.2,6.3$ & 8.66 \\
\hline 3 & $<1.6$ & $6.2,6.9,7.5$ & 8.95 \\
\hline 4 & $<1.6$ & $3.8,5.1,7.3$ & 9.72 \\
\hline 5 & $<1.6$ & $4.5,5.4,7.9$ & 11.2 \\
\hline 6 & $<1.6$ & $4.3,5.6,8.1$ & 11.9 \\
\hline 7 & $<1.6$ & $8.3,9.5,10.3$ & 12.3 \\
\hline 8 & $<1.6$ & $8.0,8.0,10.9$ & 15.2 \\
\hline 9 & $<1.6$ & $8.4,8.7,12.0$ & 15.3 \\
\hline
\end{tabular}

During the experimental process, chatter vibration between the cutter and work piece did not occur. In order to assess the chatter-free conditions during the experiment, the cutting forces signal was analysed to confirm that there was no abnormal forces impact and fluctuation. The experimental and simulated cutting force results of helical milling with typical cutting conditions, cutting speed $v_{c} 100 \mathrm{~m} / \mathrm{min}$, axial feed rate $f_{z a} 0.5 \mathrm{~mm} /$ tooth, tangential feed rate $f_{z t} 0.1 \mathrm{~mm} /$ tooth, were compared in Fig. 7.

The amplitude of the experimental cutting forces in comparison to the simulated cutting forces, which were typical stable force signals in Fig. $7 \mathrm{a}$ and b, has a margin of error within $10 \%$. No impact was detected. The amplitude spectrum of the experimental result shown in Fig. 7c properly matches the simulated cutting forces shown in Fig. 7d. The unmatched spectrum in the experimental cutting forces might be due to the serrate chip formation and other environmental influences.

From the observation of the experiment processes and the measurement of the machining accuracy and the cutting forces, it could be concluded that the given helical milling processing parameters can deliver the needed machining accuracy, and the operation can be chatter free within the stability limitation predicted by the presented analysis and model.

\section{CONCLUSION}

Based on the modelling of cutting forces, the machining dynamics and the chatter stability of the helical milling process have been modelled in both the time and frequency domains. The cutting forces model predicts both the interaction of the side-cutting 

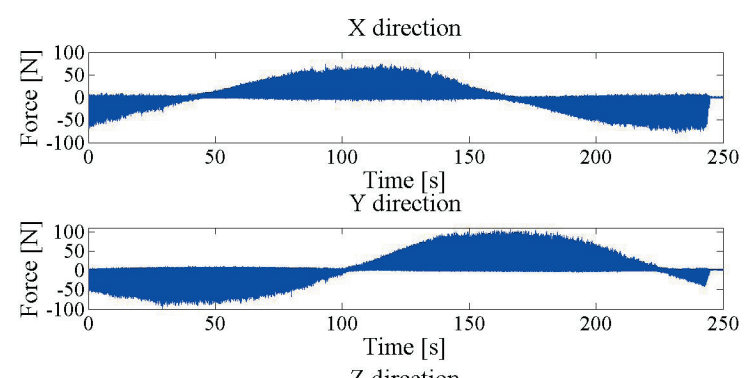

Z direction

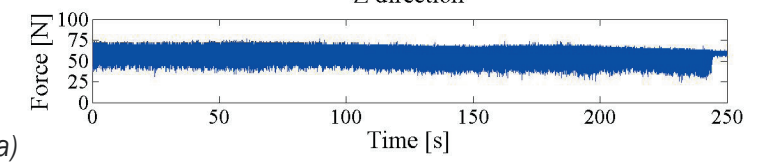

a)

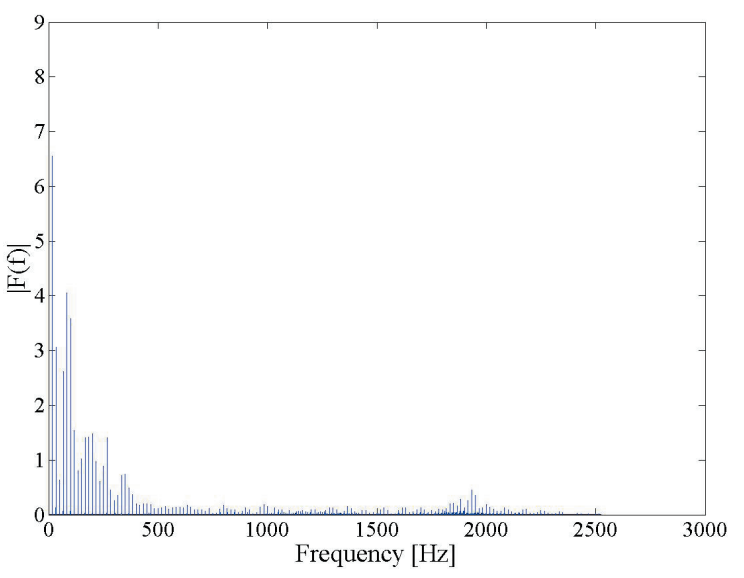

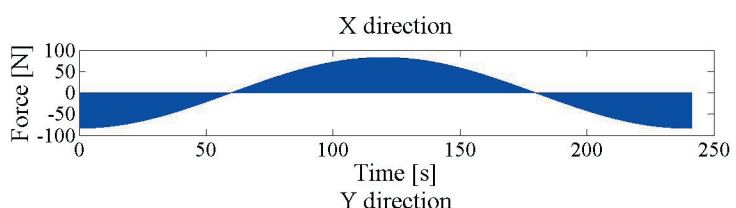

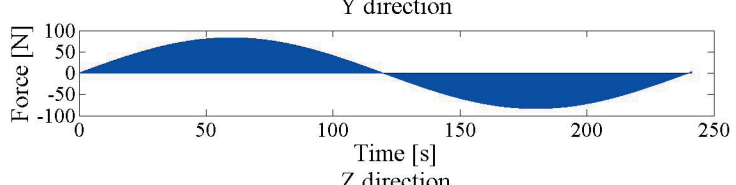

Z direction

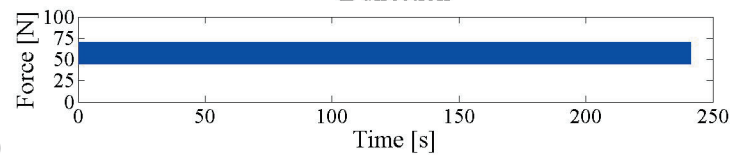

b)

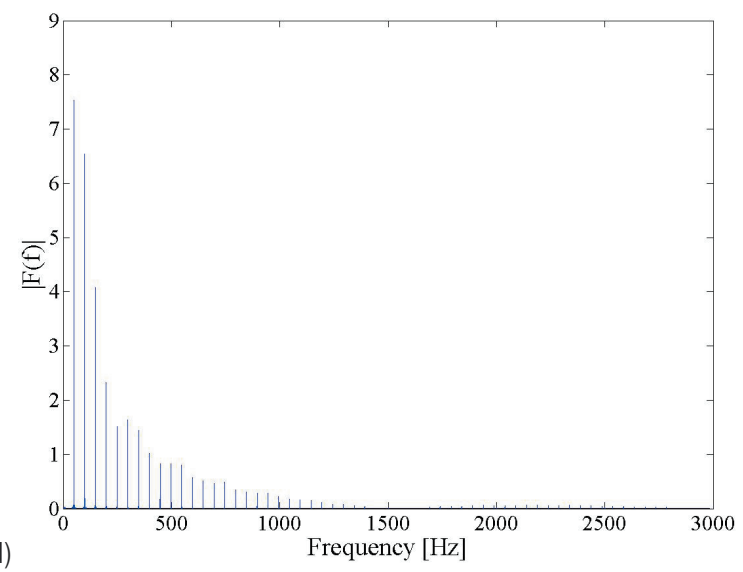

Fig. 7. Experiment and simulation of the helical milling cutting forces results; a) experiment; b) simulation; c) amplitude spectrum by Fourier transform of experiment; and d) amplitude spectrum by Fourier transform of simulation

edges with the work piece and the end-cutting edges with the work piece along the helical feed path. The helical milling dynamics model represents the special tangential feed and axial feed. This model includes the dual periodicity which is caused by spindle rotation, as well as the period of the helical feed of the cutting tool. The frequency domain solutions of the critical axial cutting depth and critical radial cutting depth with spindle velocity have also been identified. The 4 DOM vibration system has been decomposed to two 2 DOM systems and the critical axial cutting depth, and critical radial cutting depth have been solved separately.

On the given machining condition of the helix milling operation, the experimental results indicate that the simulation from the presented models effectively forecasts the cutting forces and chatterfree process parameters. Chatter did not occur during machining, and the helical milling operation satisfied the required surface roughness, roundness and cylindricity.

\section{ACKNOWLEDGEMENTS}

This work was supported by the Nanjing University of Aeronautics \& Astronautics Fundamental Research Funds [grant number NS2013048].

\section{REFERENCES}

[1] Iyer, R., Koshy, P., Ng, E. (2007). Helical milling: An enabling technology for hard machining precision holes in AISI D2 tool steel. International Journal of Machine Tools \& Manufacture, vol. 47, no. 2, p. 205-210, DOI: 10.1016/j.ijmachtools.2006.04.006.

[2] Wang, H., Qin, X., Li, H., Ren, C. (2013). Analysis of cutting forces in helical milling of carbon fiberreinforced plastics. Proceedings of the Institution of Mechanical Engineers, Part B: Journal of Engineering Manufacture, vol. 227, no. 1, p. 62-74, DOI:10.1177/0954405412464328.

[3] Denkena, B., Boehnke, D., Dege, J.H. (2008). Helical milling of CFRP-titanium layer compounds. CIRP 
Journal of Manufacturing Science and Technology, vol. 1, no. 2, p. 64-69, DOI:10.1016/j.cirpj.2008.09.009.

[4] Larue, A., Altintas, Y. (2005). Simulation of flank milling processes. International Journal of Machine Tools and Manufacture, vol. 45, no. 4-5, p. 549-559, DOI:10.1016/j.ijmachtools.2004.08.020.

[5] Altintas, Y., Engin, S. (2001). Generalized Modeling of Mechanics and Dynamics of Milling Cutters. CIRP Annals - Manufacturing Technology, vol. 50, no. 1, p. 25-30, DOI:10.1016/s0007-8506(07)62063-0.

[6] Ozturk, E., Budak, E. (2007). Modeling of 5-axis milling processes. Machining Science and Technology: An International Journal, vol. 11, no. 3, p. 287 - 311, DOI:10.1080/10910340701554808.

[7] Lazoglu, I., Liang, S.Y. (2000). Modeling of ballend milling forces with cutter axis inclination. Journal of Manufacturing Science and EngineeringTransactions of the ASME, vol. 122, no. 1, p. 3-11, DOI:10.1115/1.538885.

[8] Dang, J.-W., Zhang, W.-H., Yang, Y., Wan, M. (2010). Cutting force modeling for flat end milling including bottom edge cutting effect. International Journal of Machine Tools and Manufacture, vol. 50, no. 11, p. 986-997, DOI:10.1016/j.ijmachtools.2010.07.004.

[9] Ko, J.H., Altintas, Y. (2007). Dynamics and stability of plunge milling operations. Journal of Manufacturing Science and Engineering-Transactions of the ASME, vol. 129, no. 1, p. 32-40, DOI:10.1115/1.2383070.

[10] Altintas, Y., Ko, J.H. (2006). Chatter stability of plunge milling. CIRP Annals-Manufacturing Technology, vol. 55, no. 1, p. 361-364, DOI:10.1016/S00078506(07)60435-1.

[11] Kolar, P., Sulitka, M., Janota, M. (2011). Simulation of dynamic properties of a spindle and tool system coupled with a machine tool frame. International Journal of Advanced Manufacturing Technology, vol. 54, no. $1-4$, p. 11-20, DOI:10.1007/s00170-010-29177.

[12] Mahnama, M., Movahhedy, M.R. (2010). Prediction of machining chatter based on FEM simulation of chip formation under dynamic conditions. International Journal of Machine Tools \& Manufacture, vol. 50, no. 7, p. 611-620, DOI:10.1016/j.ijmachtools.2010.03.009.

[13] Chaari, R., Abdennadher, M., Louati, J., Haddar, M. (2011). Modelling of the 3D machining geometric defects accounting for workpiece vibratory behaviour. International Journal of Simulation Modelling, vol. 10, no. 2, p. 66-77, DOI:10.2507/ijsimm10(2)2.173.

[14] Ostasevicius, V., Gaidys, R., Dauksevicius, R., Mikuckyte, S. (2013). Study of vibration milling for improving surface finish of difficult-to-cut materials. Strojniski vestnik-Journal of Mechanical Engineering, vol. 59, no. 6, p. 351-357, DOI:10.5545/ sv-jme.2012.856.

[15] Bajić, D., Celent, L., Jozić, S. (2012). Modeling of the influence of cutting parameters on the surface roughness, tool wear and the cutting force in face milling in off-line process control. Strojniški vestnik Journal of Mechanical Engineering, vol. 58, no. 11, p. 673-682, DOI:10.5545/sv-jme.2012.456.

[16] Yoon, M.C., Chin, D.H. (2005). Cutting force monitoring in the endmilling operation for chatter detection. Proceedings of the Institution of Mechanical Engineers Part B-Journal of Engineering Manufacture, vol. 219, no. 6, p. 455-465, DOI: $10.1243 / 095440505 \times 32292$.

[17] Polli, M.L., Weingaertner, W.L., Schroeter, R.B., Gomes, J.d.O. (2012). Analysis of high-speed milling dynamic stability through sound pressure, machining force and tool displacement measurements. Proceedings of the Institution of Mechanical Engineers Part B-Journal of Engineering Manufacture, vol. 226, no. A11, p. 1774-1783, DOI:10.1177/0954405412460128.

[18] Liu, C., Wang, G., Dargusch, M. (2012). Modelling, simulation and experimental investigation of cutting forces during helical milling operations. The International Journal of Advanced Manufacturing Technology, vol. 63, no. 9-12, p. 839-850, DOI:10.1007/ s00170-012-3951-4.

[19] Wang, H., Qin, X., Ren, C., Wang, Q. (2012). Prediction of cutting forces in helical milling process. The International Journal of Advanced Manufacturing Technology, vol. 58, no. 9-12, p. 849-859, DOI:10.1007/ s00170-011-3435-y.

[20] Damir, A., Ng, E.G., Elbestawi, M. (2011). Force prediction and stability analysis of plunge milling of systems with rigid and flexible workpiece. International Journal of Advanced Manufacturing Technology, vol. 54, no. 9-12, p. 853-877, DOI:10.1007/s00170-0102982-y. 